\title{
Enhanced product functionality with life cycle units
}

\author{
G Seliger*, A Buchholz and U Kross \\ Department of Assembly Technology and Factory Management, Institute for Machine Tools and Factory \\ Management (IWF), Technical University Berlin, Berlin, Germany
}

\begin{abstract}
Cycle economy is not only ecologically reasonable but also a chance for new business. Selling utilization instead of selling products is advantageous once additional costs for information processing and logistics are less than costs for underutilized capacity. A competitive provider offers product functionality in quality, time and location as required by the user. Lifetime component monitoring is conditional for this performance. Modern microelectronic technology enables the acquisition of component deterioration with sensorial devices, information processing and storing with microcontrollers and initiating appropriate actions such as maintenance. The architecture of a microsystem called the life cycle unit (LCU) for product and component monitoring is introduced and specified. Product examples illustrate some application areas.
\end{abstract}

Keywords: life cycle unit, diagnosis, product assessment, disassembly, reuse, adaptation, train bogie

\section{INTRODUCTION}

The current management practices and the standard of living cause an increase in resource consumption. The demand for production, utilization and disposal increases owing to population growth and growing product requirements. Ecological limits will be exceeded and the available resources will be exploited in the medium term [1]. Meeting the increasing demands can only be made ecologically compatible if energy and resource consumption per head is reduced drastically [2]. The objective is to achieve more utilization with fewer resources by product reuse. Hence it follows that the utilization productivity of resources has to increase. This increase can be reached by a sustainable cycle economy considering ecological as well as economical chances [3]. Cycle economy is not only ecologically reasonable but also a chance for new business areas such as sale of product utilization or adaptation [4]. To implement this kind of sustainable cycle economy, products must be designed considering their whole life cycle, starting from the development along their utilization up to their reuse or disposal [5].

The MS was received on 20 December 2002 and was accepted after revision for publication on 14 May 2003.

*Corresponding author: Department of Assembly Technology and Factory Management, Institute for Machine Tools and Factory Management (IWF), Technical University Berlin, Pascalstrasse 8-9, D-10587 Berlin, Germany.

\section{SELLING UTILIZATION INSTEAD OF SELLING PRODUCTS}

When selling products, an essential element of profit is the decline of marginal unit costs on account of large lot sizes. The resulting resource consumption is not of too much concern. All costs of purchase, operation, maintenance and disposal of the product are at the expense of the product buyer. If the product is not in use, the product buyer as owner has to bear the idle capacity costs. Furthermore, selling replacement products is a big business, and the manufacturer has a limited interest in a long product life. However, a disadvantage of selling products compared with selling their utilization is the tendency towards higher resource consumption costs and higher costs of underutilization.

The utilization buyer pays only for the utilization of the product and not for the product itself. The costs of investment, operation, maintenance and disposal are cared for by the utilization seller. The old-style product manufacturer and seller develops into a utilization seller and service provider of components and products, while the utilization seller is interested in a long-lasting and robust product that causes little costs throughout its usage. Such a product decreases resource consumption compared with a product under the selling products paradigm.

Utilization sellers as service providers are able to offer better integrated application and service performance with their knowledge about user habits, and a customtailored usage package can be offered to utilization 
buyers [6]. Leasing, rent and service contracts, systemaccompanying quality management and information and communication systems guarantee product pursuit and product access by the supplier at the end of a usage phase. A balanced strategy of preventive maintenance and repair preserves or even increases the residual value of products [7].

Utilization sellers gain satisfied and bound customers by addressing them with a comprehensive application and service performance, although utilization buyers will hardly develop an emotional closeness to a bought usage. To be able to offer the product utilization over several usage phases, the utilization seller needs to adapt the product according to changing technical necessities and user needs in different usage phases. An appropriate adaptation is necessary for transferring the product to a further usage phase and by this enabling a continuous utilization with the same resources. Types of adaptation are maintenance, repair, remanufacturing, upgrading, downgrading, enlargement, reduction, rearrangement and modernization. The adaptation process requires disassembly and reassembly. Additional processes may include cleaning, treatment, component supply/removal, inspection and sorting.

Selling utilization becomes competitive with selling products once the idle capacity costs of a sold product are higher than the costs for logistics, information management and adaptation (Fig. 1) [8]. Thus, the right component is made available in time at the right place in adequate quality for sufficient usage. The utilization provision, the coordination of different services and users, the distribution and redistribution of products and especially the adaptation itself has to be organized to enable a high utilization of the products. It is important that selling utilization can only be competitive with product ownership when it delivers a level of customer satisfaction similar or better to that of product ownership.

The business area of selling utilization generates new requirements on the products. The service provider needs to know the product status, which may consist of product position, user identification, degree of utilization and remaining lifetime. To adapt a product in a simple and cheap manner, information like the devaluation degree of components or a disassembly plan has to be provided at the right time and place. The gathered information may be delivered to the service provider using wireless information technology. The presented functions can be provided by an integrated technical system, which encompasses the acquisition, processing, storage and transmission of information as well as acting on the basis of this information. Such a system is developed under the term life cycle unit (LCU).

\section{LIFE CYCLE UNIT}

Devaluation limits the usage time and quality of products and can be divided into physical changes and changed requirements. Utilization leads to physical changes such as ageing, breakage, corrosion, creep, deformation, fatigue, loss/displacement, pollution and wear, which are caused by biological, chemical, electrical, magnetic, mechanical, radiation or thermal mechanisms [9]. Their extent is determined by product characteristics such as material or treatment and external influences such as temperature or dust, and by the type of usage. Changed requirements can result from technical progress, legal amendments, a change in values, fashion trends or a converted usage and are attributed to parameters such as purpose, duration, place or intensity of usage, policy, society and economy. Knowledge about physical changes, components, paths of adaptation and other product features is required for the disassembly of devaluated products and to reassemble and distribute adapted products for later usage phases. The microsystem technology offers new potentials for acquiring the product status of components by sensors, for data processing, storage and transfer by microelectronics and for compensating
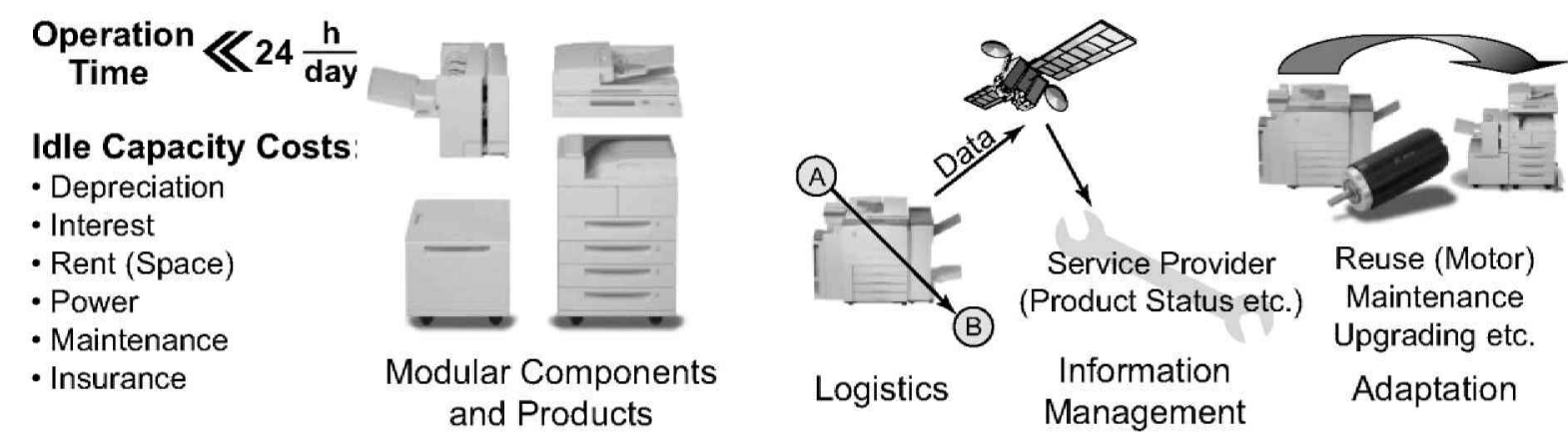

\section{$\sum$ Idle Capacity Costs $\rangle \sum \begin{aligned} & \text { Costs for Logistics, Information Management, } \\ & \text { and Adaptation (Functionality in Time and Place) }\end{aligned}$}

Fig. 1 Premise for selling utilization instead of selling products 

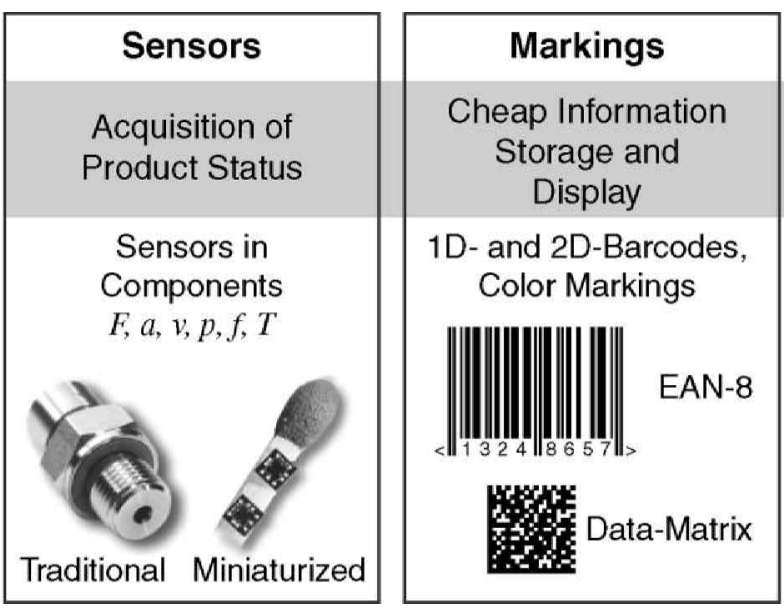
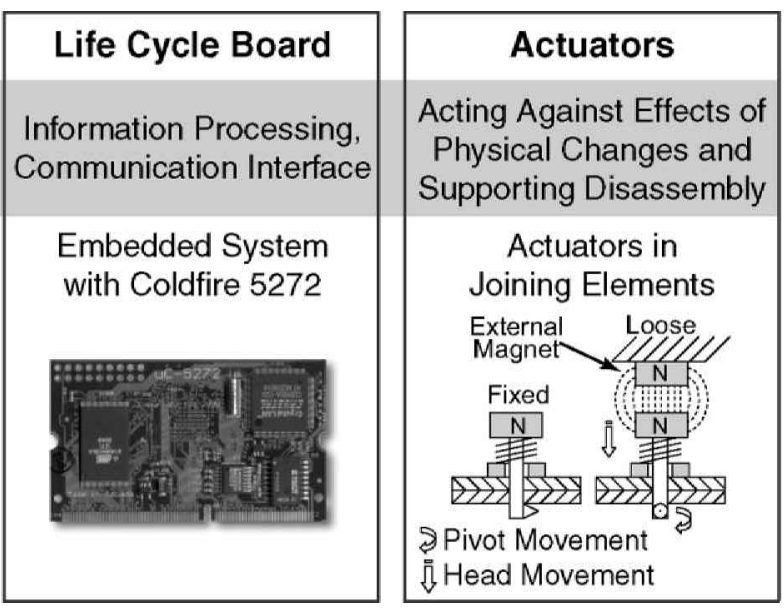

Fig. 2 Four elements of the LCU physical changes and initiating disassembly by actuators [10].

The LCU system consists of four elements: sensor, marking, life cycle board (LCB) and actuator, as can be seen in Fig. 2. Sensors, or transducers, are integrated in components, acquire the product status and monitor safety-relevant joining elements. Information may be displayed in a coded way with the help of markings in order to ease their sensorial acquisition and decoding. The LCB is able to process, store and transfer information with its three elements: processor, memory and interface. Actuators may act against the effects of physical changes and are controlled by the LCB. A second task of actuators is the intelligent disassembly by using joining elements with integrated actuators. To disassemble the joint, an electromagnet has to be positioned close to the head. After activating the electromagnet, the joint may be released.

The LCB is currently being developed in SMD Technology using a Motorola Coldfire MC5272 microcontroller. It runs the operating system uCLinux, an embedded version of Linux, which enables various ways of communication such as Bluetooth, Ethernet, IrDA, GSM or WLAN. For many applications, the basic LCB has to be equipped with appropriate sensors and actuators. In order to obtain dynamic data such as information about the actual status of the application, it is necessary to establish a model of the devaluation process, to classify the occurring physical changes and to select sensors that detect the relevant changes. The devaluation model will be incorporated into the LCU software. If only static product data such as product identification or disassembly information have to be stored, the LCU may deliver it without the need for reliability models. To supply static product data at minimal costs, markings can be a cheap alternative to an LCB. They are passive information memories and do not require any energy supply to provide information. Examples are paint markings or barcodes, and systems for coding, identifying and decoding of disassembly information stored with markings have been developed.

Finally, the whole LCU can be produced as a modular microsystem, where all components are integrated in one small system. In this way, the advantages of microsystem technology such as decline of marginal unit costs, higher reliability due to smaller structures, lower energy consumption or accessibility to areas that are not accessible for usual technologies will show through.

For identifying useful LCU functionalities, it is helpful to show product application characteristics and information processed by the LCU. Figure 3 gives a first glance of the combinatorial solution space.

The above information is important for multiple interest groups: manufacturers of consumer and capital goods would like to determine the product status,

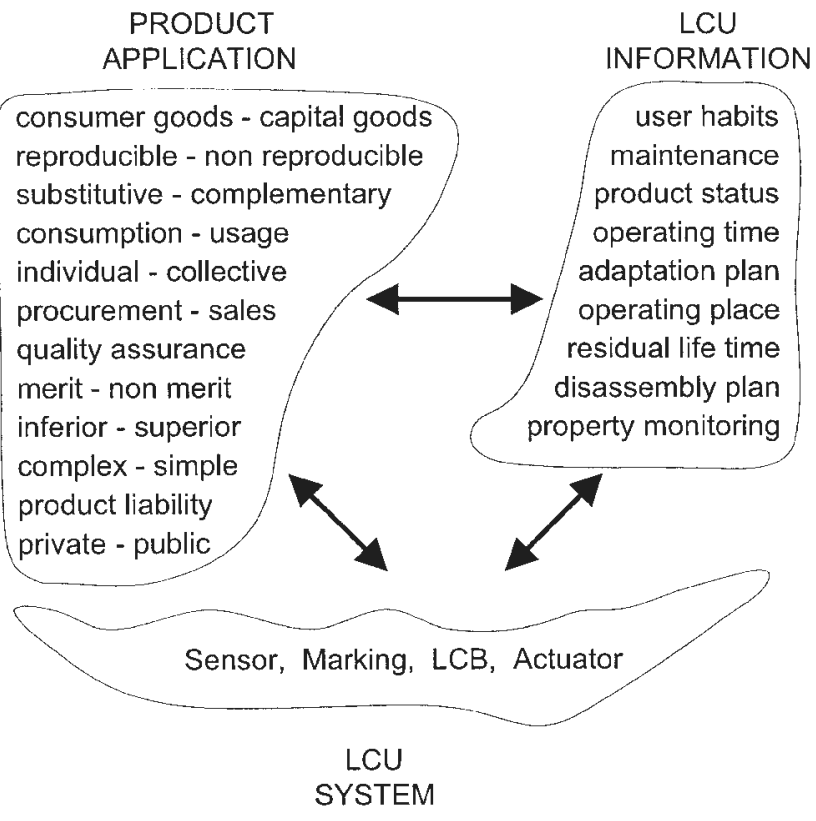

Fig. 3 Solution space for LCU functionality design

Proc. Instn Mech. Engrs Vol. 217 Part B: J. Engineering Manufacture 
causes of failures and warranty injuries [11]. Disassembly factories and maintenance services are interested in stored disassembly plans and maintenance information. The documented user habits could be interesting for advertising agencies. Public authorities such as an environmental agency are interested in monitoring emission standards of non-merit goods. Leasing companies such as a service provider of photocopiers want to maintain their fleet in a preventive way, and a logistics service would like to know the accurate position and status of the transported goods at all times.

\section{AREAS OF APPLICATION}

Two applications being prototypically realized for evaluation are described in the following figures. In the first example, an LCU for the acquisition and evaluation of product status data of a car is presented in Fig. 4. Sensors detect the pressure on the crankcase, the ignition currents, the angular speed of the motor, the oil velocity, oil pressure and oil temperature, the water temperature and the combustion strength. The position of the car is detected via the global positioning system (GPS) and transferred to the service provider using radio transmission.

In the course of deregulation of German freight railway operation, the competition leads to the increased fulfilment of end-customer needs for transport use. These are mainly less transport cost, information on freight location and condition, freight security, higher average speed and accuracy. With the telematics-based LCU wagon, owners could fulfil these needs by higher availability, safety and more effective maintenance, GPS-receiver and sensor technology in loading space, antitheft devices, decreased time for train coupling and reliability.

The acquisition of the parameters enables a prediction of the devaluation in the car and possible means for its improvement. The car utilization provider can inform the user about a scheduled maintenance and supply a replacement car in time. Through its documentation possibilities, the utilization provider obtains information about the user's habits and knows where the car is located which is useful in case of accidents or theft. The quality assurance of products is another aspect and with LCUs can be extended from design/production phase into the usage phase/post-usage phase. Today, quality assurance instruments are only applied during the usage phase of products in the form of field data and loss analyses evaluation. Enhanced quality assurance instruments delivering information from the product usage phase relevant for designs of new products, etc., can be realized using LCUs. This becomes more and more interesting in markets with decreased development times (e.g. mobile phones).

In the second example, an LCU is implemented in a freight wagon bogie [12]. The main wear componentsaxle bearing, wheel, brake and spring (see Fig. 5) affect the maintenance activities. Measuring the stress values

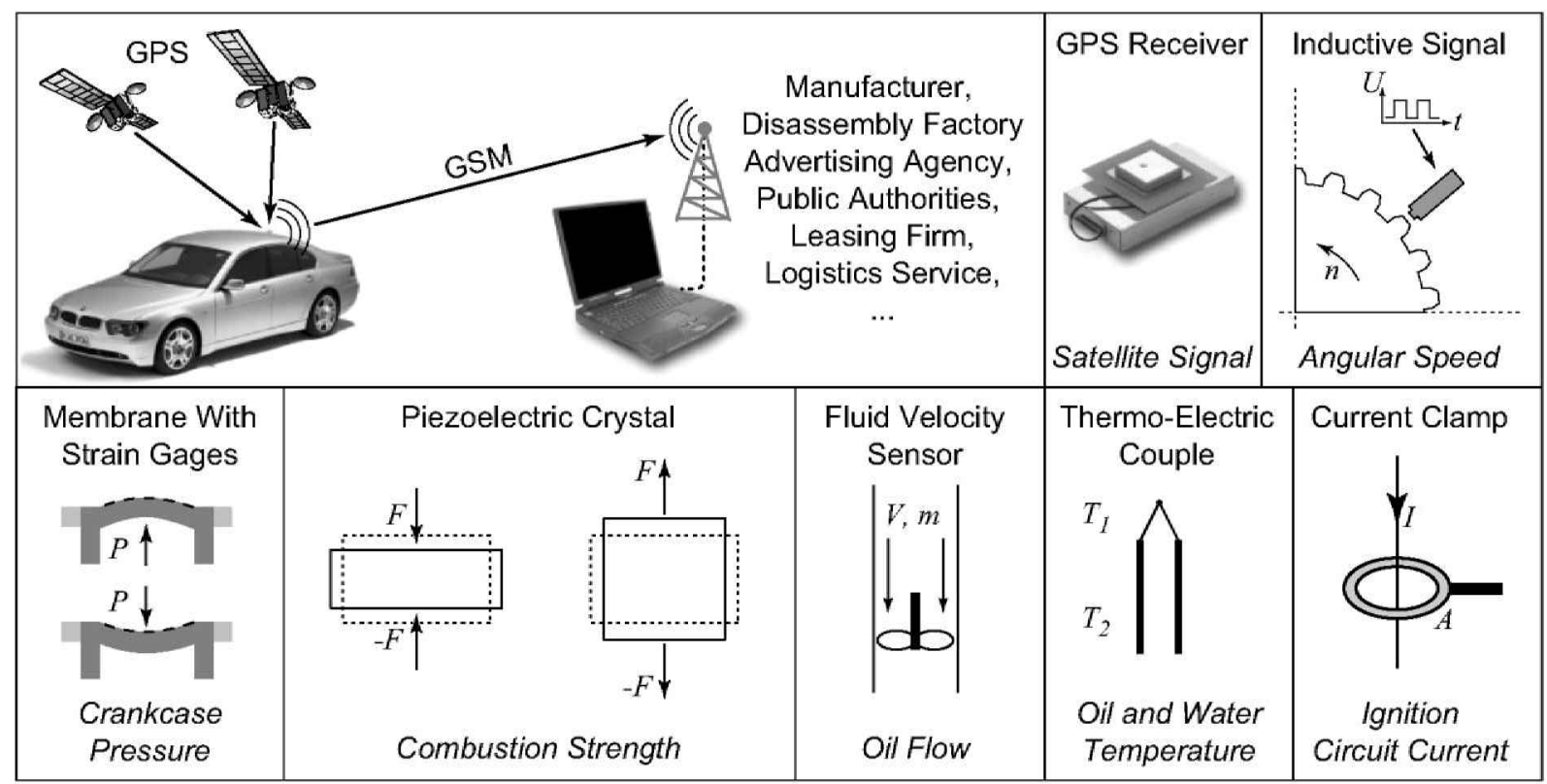

\footnotetext{
Legend: Sensor Principle; Measurable Variable

GPS = Global Positioning System

GSM = Global System for Mobile Communications
}

Fig. 4 Acquired and transferred data of the car LCU 


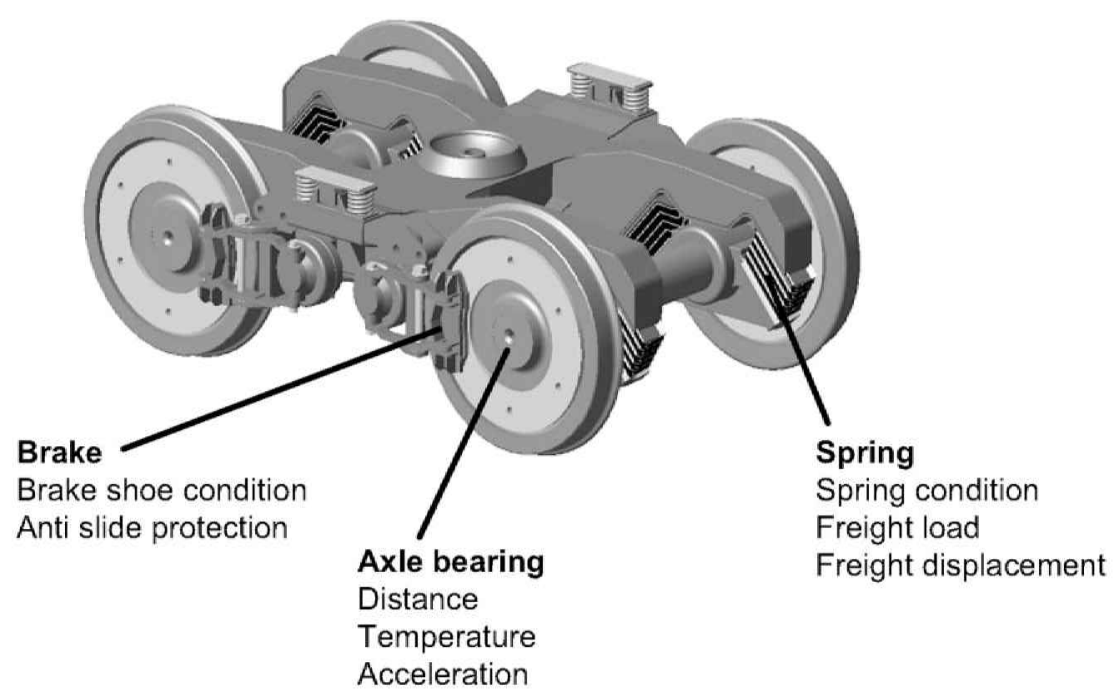

Fig. 5 LCU-monitored parameters of a freight wagon

in relation to the real operation performance is used to estimate the condition of the components by calculating continuously their wear life span equations. When reaching defined thresholds, the LCU transfers information using GSM to a central office that plans and coordinates the maintenance activities with temporal advance. In addition to that, the safety-relevant bearings of the bogie are supervised regarding temperature and acceleration in order to prevent derailment resulting from stuck or broken bearings. The exceeding of threshold values leads to emergency actions, for instance the reduction of train velocity. When coupling the wagons to trains, the LCUs of all train bogies report the operativeness of the brakes to the locomotive using a separate bus. The time consuming manual control of each brake that is done by wagon inspectors today can be omitted.

\section{CONCLUSIONS}

An increasing utilization productivity of resources is a fundamental ecological requirement of mankind continuously improving the standard of living. Multiple usage phases of useful products and components can contribute to more prosperity with less resource consumption. Sale of utilization becomes economically competitive with product sale once innovative services empowered by the potentials of modern information and communication technology enable the saving of idle capacity costs. Technologically, the challenge of component adaptation to customer requirements related to time, place and quality is met by the modular design of the life cycle unit (LCU) microsystem combined with respective logistics. The profit paradigm of a maximum number of products sold to minimum costs of manufacturing is provoked by that of maximum utilization and functionality sold to minimum costs of resource consumption.

\section{ACKNOWLEDGEMENT}

This paper presents results of the Collaborative Research Center 281 'Disassembly Factories for the Recovery of Resources in Product and Material Cycles' (SFB 281), financially supported by the Deutsche Forschungsgemeinschaft (DFG).

\section{REFERENCES}

1 v. Weizsäcker, E. U., Lovins, A. B. and Lovins, L. H. Faktor Vier: Doppelter Wohlstand-halbierter Naturverbrauch, 1995 (Droemer Knaur, Munich, Germany).

2 Schmidt-Bleek, F. Das MIPS-Konzept, 1998 (Droemer Knaur, Munich, Germany).

3 Zussman, E., Kriwet, A. and Seliger, G. Disassembly oriented assessment methodology to support design for recycling. Ann. CIRP, 1994, 43(1), 9-14.

4 Westkämper, E., Feldmann, K., Reinhart, G. and Seliger, G. Integrated development of assembly and disassembly. Ann. CIRP, 1999, 48(2), 557-566.

5 Alting, L. and Brobech Legarth, J. Life cycle engineering and design. Ann. CIRP, 1995, 44(2), 569-580.

6 Kimura, F., Hata, T. and Suzuki, H. Product quality evaluation based on behaviour simulation of used products. Ann. CIRP, 1998, 47(1), 119-122.

7 Seliger, G., Müller, K. and Perlewitz, H. More use with fewer resources. In Proceedings of 4th CIRP International Seminar on Life Cycle Engineering, Berlin, Germany, 1997, pp. 3-16.

8 Seliger, G., Perlewitz, H., Wiendahl, H.-P. and Bürkner, S. A general approach to disassembly planning and control. Prod. Planning and Control, 1999, 10(8/99), 718-726. 
9 Grudzien, W. Beitrag zur Steigerung der Nutzenproduktivität von Ressourcen durch eine Life Cycle Unit. Dissertation, TU Berlin, Germany, 2002.

10 Van Brussel, H., Peirs, J., Reynaerts, D., Delchambre, A., Reinhart, G., Roth, N., Weck, M. and Zussman, E. Assembly of micro-systems. Ann. CIRP, 2000, 49(2), 451-472.
11 Addy, P., Buchholz, A., Franke, C., Middendorf, A., Reichl, H. and Seliger, G. Einsatz produktbegleitender Informationssysteme und ihre Auswirkungen auf die Produktionstechnik. TU Berlin, Germany, October 2002.

12 Hecht, M. In search of a quieter, lighter freight bogie. Railway Gaz. Int., September 2002, 563-568. 